\title{
Research on Weld Formation Mechanism of Laser- MIG Arc Hybrid Welding with Butt Gap
}

\author{
Hanxuan Huang ${ }^{1,2}$, Peilei Zhang ${ }^{1,2^{*}}$, HuaYan ${ }^{1,2}$, Zhengjun Liu ${ }^{1,2}$, Zhishui Yu ${ }^{1,2}$, Di Wu ${ }^{1,2}$, Haichuan Shi ${ }^{1,2}$, \\ Yingtao Tian ${ }^{3 *}$ \\ ${ }^{1}$ School of Materials Engineering, Shanghai University of Engineering Science, Shanghai 201620, China \\ ${ }^{2}$ Shanghai Collaborative Innovation Center of Laser Advanced Manufacturing Technology, Shanghai \\ 201620, China \\ ${ }^{3}$ Department of Engineering, Lancaster University, Bailrigg, Lancaster LA1 4YW, United Kingdom
}

Abstract: At present, there are few researches on laser -MIG arc hybrid welding with a large butt gap. In this paper, laser-MIG arc hybrid welding is used to weld low-alloy high-strength steel with a thickness of 3mm, and a laser-MIG arc hybrid welding process under large gap conditions is developed. This paper studies the effects of arc voltage, laser-wire distance, and wire feed speed on the gap bridging capability of hybrid welding under different butting gaps were studied. Under the condition of the $1 \mathrm{~mm}$ butt gap, the influence mechanism of laser-wire distance on weld the weld formation of hybrid welding is analyzed by combining high-speed photography, welding current and voltage waveform, the macroscopic and microscopic morphology of the weld. The results show that there are optimal process parameter values for the effects of arc voltage and laser-wire distance on the gap bridging capability of hybrid welding. Adjusting the laser-wire distance can optimize the energy distribution of laser on the welding wire and weld pool, thus controlling the arc current, voltage, and droplet transition mode, and finally affecting the weld penetration and forming. When the laserwire distance is $0 \mathrm{~mm}$, the droplet transition frequency is the fastest, and the droplet transition is a mixture of short circuit transition and liquid bridge transition. At this point, the welding rate is the fastest and the welding process is the most stable. However, by comprehensively integrating factors such as the gap bridging capability and the weld penetration, the optimal processing parameters are obtained when the laser-wire distance is $0.5 \mathrm{~mm}$.

Keywords: laser-MIG arc hybrid welding, laser-wire distance, high-strength steel, butt gap, high-speed photography 


\section{Introduction}

Laser-MIG arc hybrid welding is a new and efficient welding process that organically combines the laser heat source and the arc heat source. It has the advantages of both laser welding and arc welding ${ }^{[1]}$. By effectively using the laser heat source, the stability of the arc can be maintained while the welding speed is increased, and the problem of insufficient penetration of the arc welding can be addressed at the same time $^{[2-3]}$. On the other hand, the use of arc heat sources can make up for the problem of poor adaptability of laser welding under wide gap machining conditions. It can also improve the poor welding effect of the laser on highly reflective materials ${ }^{[4-5]}$. Therefore, the laser-MIG arc hybrid welding technology can meet the processing requirements of wide gaps and high welding speeds in industrial production. While improving production efficiency, it can reduce the requirements for clamping accuracy in industrial production, and ultimately still obtain good welding results. These advantages make it become one of the most promising and efficient welding technologies in the industry ${ }^{[6]}$.

However, under the condition of a large butt gap, a good welding effect is inseparable from a suitable welding process. The welding process of laser-MIG arc hybrid welding is relatively complicated, and the factors such as laser-wire distance, arc parameters, and laser power all affect the final welding effect ${ }^{[7]}$. Mahmoud et al ${ }^{[8]}$ proposed that the increase of arc voltage would lead to the arc becoming longer and wider and drift, resulting in unstable droplet transition, which would further reduce the stability of the welding process. And they found that too small a laser-wire distance and lower laser power can cause unstable welding processes. However, it did not explore the relationship between the laser-wire distance and arc voltage, and their influence on the gap bridging ability of laser-MIG arc hybrid welding. Liu et al. found that laser plasma has low resistivity as the starting point of conductive channel formation. Besides, laser energy has a huge impact on arc length and droplet transition ${ }^{[9-10]}$. Kah et al. ${ }^{[11]}$ illustrates the importance of shielding gas to the laser arc hybrid welding process. Yang et al. ${ }^{[12]}$ believes that a larger shielding gas flow can effectively improve weld formation and enhance welding results. Meng et al. ${ }^{[13]}$ introduced the arc increment coefficient to 
characterize the strength of the synergistic effect of laser and arc when studying the synergistic effect of laser arc hybrid welding. They found that the synergistic effect of hybrid welding becomes stronger as the laser power increases, but it decreases as the arc current increases. Bunaziv et al. ${ }^{[2]}$ proposed that the parameters of the arc will change the pressure of the arc, thereby affecting the flow of the molten pool and ultimately affecting the formation of the weld. Tang et al. ${ }^{[14]}$ found that the positional relationship between the arc and the laser has an important effect on the hump formation of the weld. Compared with laser-guided laser-MIG arc hybrid welding, the arc-guided droplet transfer cycle is longer and droplet diameter is smaller, so the pool weight accumulates more slowly. This helps slow down the increase in gravity at the root of the molten pool and suppress the occurrence of the hump. Moreover, arc-guided has higher electrical parameter stability than laser-guided. J.L. Zou et al. ${ }^{[15]}$ in the study of the impact of the paraxial TIG on high-power fiber laser welding, found that laser-arc hybrid welding can reduce the negative impact of plume on welding, thereby improving laser energy utilization and welding penetration. The laser-wire distance and arc current also have a significant effect on the laser plasma plume. Regrettably, it has not further studied the effect mechanism of the laser-wire distance on the weld formation. Liu et al. ${ }^{[16]}$ studied the laser-wire distance, they found that the laser-wire distance has a significant effect on the arc characteristics, the weld bead geometry, and the droplet transfer mode. A suitable arc distance can effectively improve the stability of the welding process. But they did not discuss the mechanism of the effect of the laser-wire distance on the weld under a certain butt gap.

To sum up, previous studies mainly explored the effect of factors such as laser power, arc parameters, and shielding gas on the forming of hybrid welding seams. However, the influence of laser-wire distance on gap bridging ability of laser -MIG arc hybrid welding, the influence of laser-wire distance on weld forming, and forming mechanism of laser -MIG arc hybrid welding are seldom mentioned. Laser-wire distance as a vital process parameter in laser -MIG arc hybrid welding. It can change the energy distribution of the laser on the welding wire and the molten pool, which plays an indispensable role in improving the gap bridging ability of welding and weld 
forming. In this paper, for HR420LA low alloy high strength steel, a laser-MIG arc hybrid welding process under large gap conditions has been developed. Furthermore, the effects of arc voltage and laser-wire distance parameters on the gap bridging ability of hybrid welding were studied, and the mechanism of the effect of laser-wire distance on the forming of hybrid welding seams were analyzed by combining high-speed photography, welding current and voltage waveforms. And the application of laserMIG arc hybrid welding large gap high welding speed forming mechanism to improve the welding process is very instructive for industrial production.

\section{Experimental}

\subsection{Experimental materials}

The base material used in the experiment is HR420LA (Hot Rolled 420 Low Alloy Steel). Hot rolled low-alloy high-strength steel plate with a yield strength of $420 \mathrm{Mpa}$. The size is $100 \mathrm{~mm} \times 100 \mathrm{~mm} \times 3 \mathrm{~mm}$. Using Lincoln Electric Company's JM-56 highstrength copper-plated welding wire, welding wire diameter is $1.2 \mathrm{~mm}$, MIG welding shielding gas uses pure argon with a volume fraction of $99.99 \%$. The base metal and wire composition are shown in Table 1.

Table 1 Chemical composition of high-strength steel and ER50-6 wire (wt.\%)

\begin{tabular}{ccccccccc}
\hline & $\mathrm{C}$ & $\mathrm{Si}$ & $\mathrm{Mn}$ & $\mathrm{Ni}$ & $\mathrm{Ti}$ & $\mathrm{Nb}$ & $\mathrm{Cu}$ & $\mathrm{Fe}$ \\
\hline HR420LA & $\leq 0.1$ & $\leq 0.5$ & $\leq 1.6$ & - & $\leq 0.15$ & $\leq 0.009$ & - & Bal. \\
JM-56 & 0.07 & 0.88 & 1.49 & $\leq 0.15$ & - & - & $\leq 0.5$ & Bal. \\
\hline
\end{tabular}

\subsection{Experimental methods}

In this experiment, a laser-MIG arc hybrid welding system was set up. The experimental system is mainly composed of laser systems, MIG welding systems, motion systems, and auxiliary equipment. The system is stable and efficient, and it can realize long-distance flexible processing through an optical fiber. The laser system consists of the IPG YLS-5000 fiber laser from IPG Photonics in the United States, a transmission fiber with a core diameter of $200 \mu \mathrm{m}$, and a HIGHYAG welding laser head. The laser wavelength is $1067 \mathrm{~nm}$, the working mode is a continuous wave, the beam 
quality is $4 \mathrm{~mm} \cdot \mathrm{mrad}$, and the focal spot diameter is $0.42 \mathrm{~mm}$. The MIG welding system consists of a KempArc450MIG welding machine, wire feeder from KEMPPI, Finland, in addition to that RM $42 \mathrm{~W}$ water-cooled welding gun from German TBI company. The kinematic system consists of KR 60 HA six-axis robot from KUKA, Germany. Auxiliary equipment used Phantom VEO710L high-speed camera from Vision Research Company of America. To achieve clear shooting, choose Nikon AIR MIRCO NIKKOR200mm1:4D telephoto lens, and 810 $\pm 10 \mathrm{~nm}$ narrow band filter, and Finland CAVITAR company's maximum power $500 \mathrm{~W}$ semiconductor pulse laser as the backlight source. Furthermore, Keysight InfiniiVision 4000X series oscilloscope was used to record the welding process and collect welding electrical signals. The welding device and heat source distribution method of laser-MIG arc hybrid welding are shown in Figure 1.

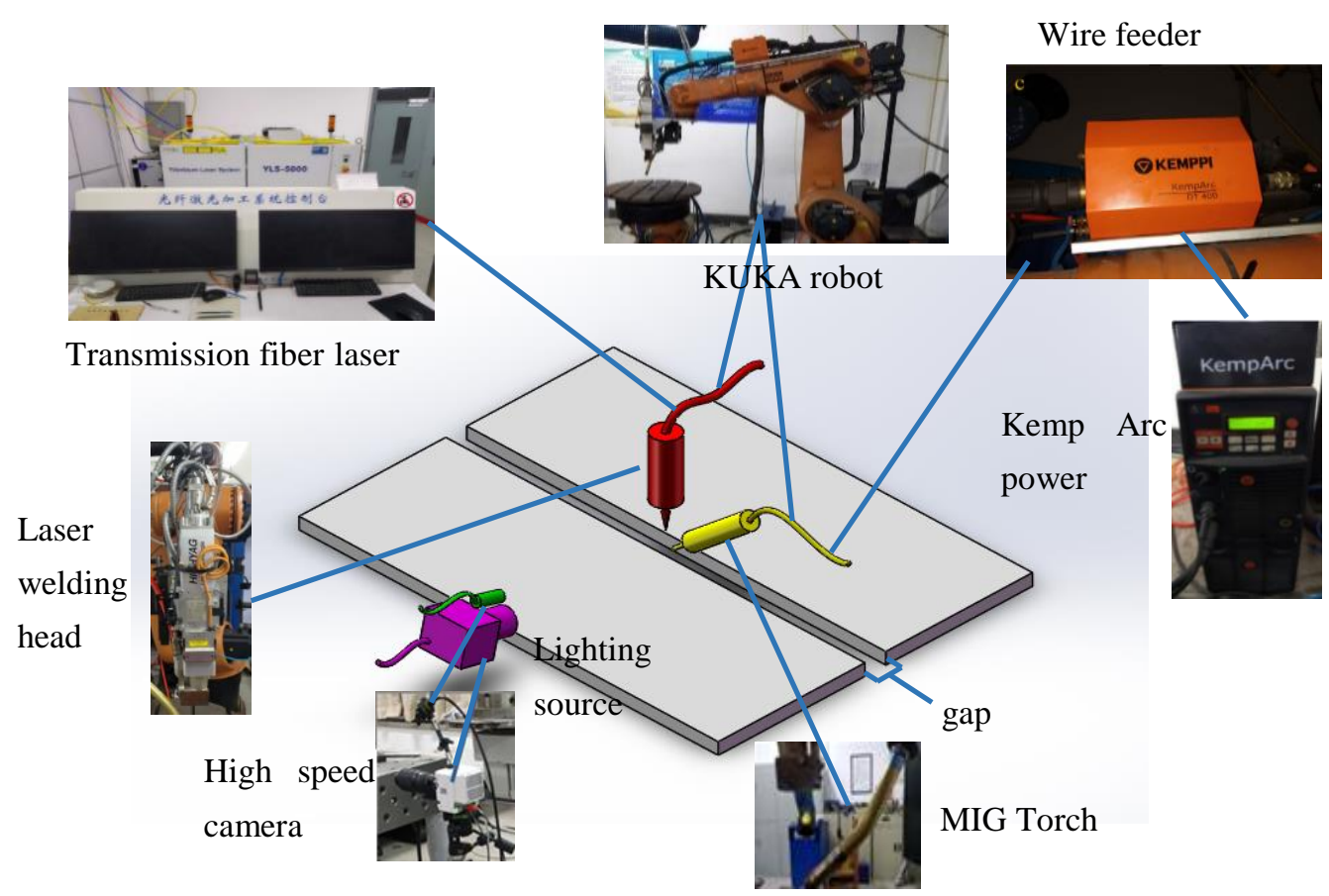

Fig.1 Schematic diagram of laser-arc hybrid welding setup with gap condition

The variable gap butt method was used in the experiment. The gap bridging capability of laser-MIG arc hybrid welding was studied using HR420LA high strength steel plate with a butt gap of $0 \mathrm{~mm}$ at the beginning and a butt gap of $2 \mathrm{~mm}$ at the end. The structure of the variable gap steel plate is shown in Figure 2. Considering that the laser-leading may not work on the workpiece under large gaps. Besides, Liu et al. ${ }^{[1]}$ 
also showed that the arc-guided hybrid weld has better microstructure and mechanical properties. So the laser is placed after the arc. In this way, smaller laser power can also be used to achieve a large gap butt welding of laser-MIG arc hybrid welding at a higher welding speed, thus reducing the laser energy and saving costs. The optimal laser power and other process parameters were determined through experiments, and then the arc voltage, the laser-wire distance, and the wire feed speed were changed respectively to study the gap bridging ability of the laser-MIG arc hybrid welding. Calculate and compare its maximum gap bridging ability by measuring the welding length limit of laser-MIG arc welding. The main process parameters are shown in Table 2. The left column is the process parameters when studying the arc voltage, and the right column is the process parameters when studying the laser-wire distance. Then the butt gap of the base material was fixed to $1 \mathrm{~mm}$, and the hybrid welding experiment is performed with different laser-wire distance. Using a high-speed camera to observe the droplet transition in the molten pool. Acquisition of welding electrical signals using an oscilloscope. The main process parameters are shown in Table 3. After the above experiment is completed, cut the sample along the cross section. Then corrosion of welds with $4 \%$ by volume nitric acid alcohol. The morphology of the weld was observed by the vhx-5000 ultra depth of field microscope (OM) from KEYENCE, Japan.

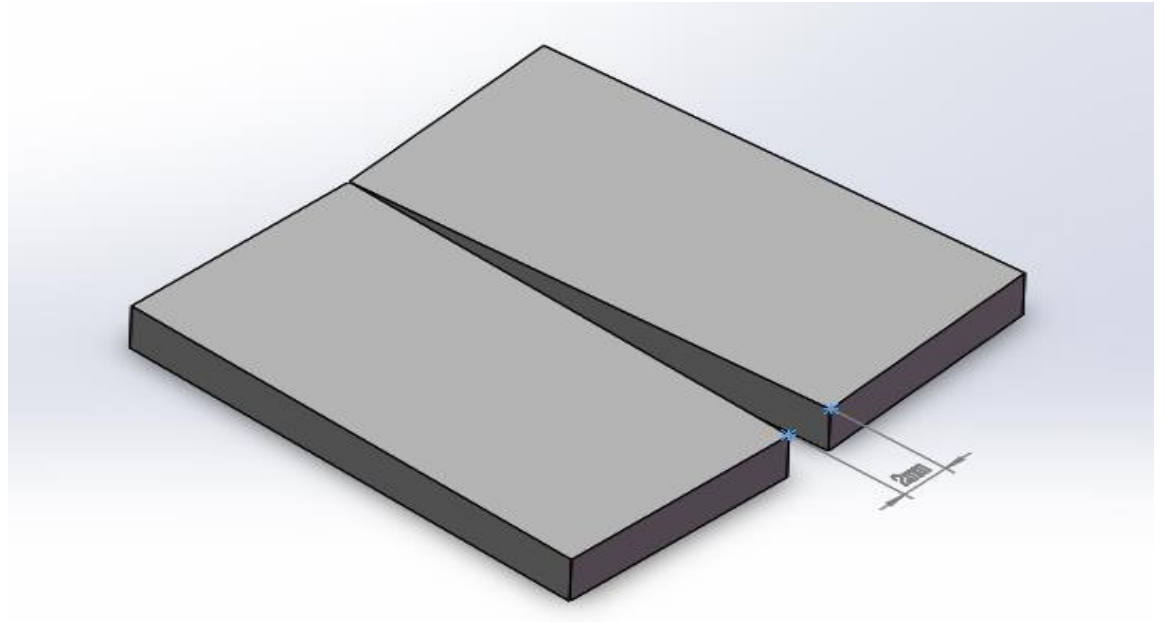

Fig.2 Research method of gap bridging ability in laser-MIG hybrid welding 
Table 2 Process parameters of the effect of arc voltage and laser-wire distance on gap bridging ability of laser-MIG arc hybrid welding

\begin{tabular}{|c|c|c|c|}
\hline Parameters & Value(arc voltage) & Value(laser-wire distance) & Value(wire feed speed) \\
\hline Arc voltage/V & $12 \sim 32$ & 16 & 16 \\
\hline Laser Power/W & 2000 & 2000 & 2000 \\
\hline Welding Speed $/ \mathrm{m} \cdot \mathrm{min}^{-1}$ & 2 & 2 & $4 \sim 10$ \\
\hline Defocusing Distance/mm & -2 & -2 & -2 \\
\hline Wire Feeding Speed $/ \mathrm{m} \cdot \mathrm{min}^{-1}$ & 4 & 4 & 4 \\
\hline Angle of welding torch $\left(^{\circ}\right)$ & 35 & 35 & 35 \\
\hline Distance of Laser and Wire/mm & 0 & $-2 \sim 4$ & 0 \\
\hline Shield Gas Flow Rate $/ \mathrm{L} \cdot \mathrm{min}^{-1}$ & 20 & 20 & 20 \\
\hline Extension Length of Welding Wire/mm & 20 & 20 & 20 \\
\hline Gap Widths of Starting Point and Ending & $0 \& 2$ & $0 \& 2$ & $0 \& 2$ \\
\hline
\end{tabular}

Table 3 Process parameters of the effect of laser-wire distance on laser-MIG arc hybrid welding under $1 \mathrm{~mm}$ gap

\begin{tabular}{cc}
\hline Welding parameters & Value \\
\hline Gap width(mm) & 1.0 \\
Laser Power/W & 2000 \\
Welding speed(m/min) & 2 \\
Wire Feeding Speed/m. min $^{-1}$ & 8 \\
Arc voltage(V) & 16 \\
Defocus amount(mm) & -2 \\
Shield Gas Flow Rate/L·min ${ }^{-1}$ & 20 \\
Distance of laser and $\operatorname{arc}(\mathrm{mm})$ & $-1 \sim 1$ \\
Angle of welding torch $\left.{ }^{\circ}\right)$ & 55 \\
Welding wire extension(mm) & 20 \\
\hline
\end{tabular}




\section{Results}

\subsection{Effect of arc voltage on gap bridging capability of laser-MIG arc}

\section{hybrid welding}

Table 4 shows the macroscopic morphology of laser-MIG arc hybrid welding seam under different arc voltages. Detailed process parameters can be seen in Table 2 . When the arc voltage is $12 \mathrm{~V}$, the maximum length of the welding seam reaches $45 \mathrm{~mm}$, and the maximum gap between the two sidewalls of the workpiece that can be melted at the same time is $0.9 \mathrm{~mm}$. After the welding seam exceeds $45 \mathrm{~mm}$, the droplets all transition to the one side of the substrate. The welding seam between $28 \mathrm{~mm}-45 \mathrm{~mm}$ has collapsed (Therefore, the actual maximum bridging gap is $0.56 \mathrm{~mm}$ ). This is because as the welding gap increases, the downward resultant force on the molten pool becomes larger, as shown in Figure 3. The arc pressure in the figure is mainly composed of the plasma flow force (Fp) and the electromagnetic contraction force (Fem). As shown in Eq. (1) ${ }^{[16]},(2)^{[18]}$ :

$$
F_{P}=\frac{C_{d} A_{p} \rho_{f} v_{f}^{2}}{2}
$$

where $C_{d}$ is the plasma flow coefficient $(\mathrm{Cd}=0.45), A_{p}$ is the action area of the plasma flow, $v_{f}$ is the velocity of the plasma flow, $\rho_{f}$ is the density of the plasma flow.

$$
\begin{gathered}
F_{e m}=\frac{u_{0} I^{2}}{4 \pi} F_{e m z} \\
F_{e m z}=-\left[\frac{1}{4}-\ln \left(\frac{r_{d} \sin \theta}{r_{w}}\right)+\frac{1}{1-\cos \theta}-\frac{2}{(1-\cos \theta)^{2}} \ln \left(\frac{2}{1+\cos \theta}\right)\right]
\end{gathered}
$$

where $I$ is welding current, $r_{d}$ droplet radius, $r_{w}$ wire radius, $\theta$ arc hanging angle and $u_{0}$ is the permeability of free space $\left(4 \pi \times 10^{-7} \mathrm{Hm}^{-1}\right)$.

As can be seen from the above equation, only changing the butt gap, $F_{P}$ and $F_{e m}$ are not affected, so the arc pressure remains unchanged. The gravity of the liquid molten pool is not affected by the butt gap. Besides, as the butt gap increases, the melting amount of the base material will be greatly reduced, so the upward force of the metal vapor on the droplet will also disappear. But the increase of the butt gap will reduce the support force of the workpiece to the liquid molten pool. And as the molten pool liquid bridge becomes flat, the tension inside the molten pool becomes smaller, so the total resultant force that causes the molten pool to collapse downward becomes larger. This will lead to the phenomenon that when the butt gap is small, the residual height of the welding seam is large; when the butt gap is large, the residual height of the welding seam is small. As shown in the sectional view of the weld in Figure 3. For a more detailed analysis of the force of the droplet, please refer to the literature ${ }^{[19]}$. So, it can be observed from the back of the weld that the $28 \mathrm{~mm}$ before the weld is not penetrated, and $28 \mathrm{~mm}-45 \mathrm{~mm}$ is formed better because the weld pool collapses.
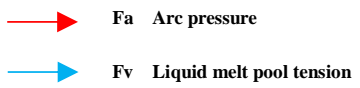

Fa Support force of workpiece to molten pool

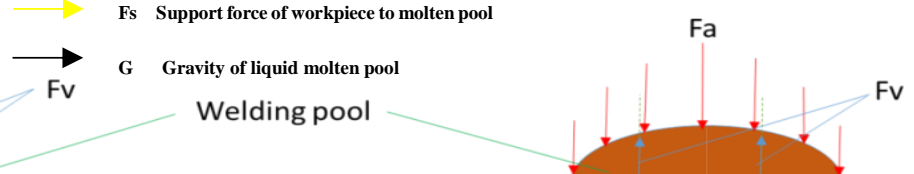



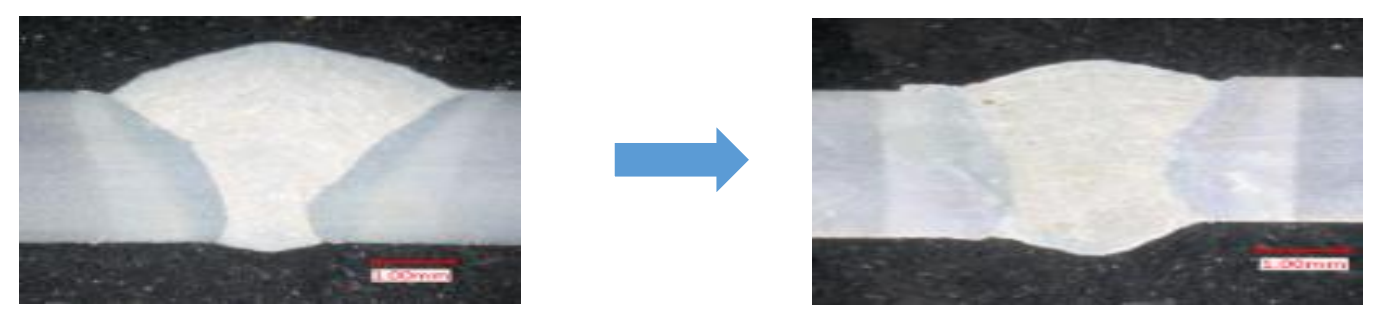

Fig.3 Stress analysis of weld pool in laser arc hybrid welding with variable gap butt joint and corresponding weld cross-sectional schematic diagram

When the arc voltage is increased to $16 \mathrm{~V}$, the weld formation is significantly improved and the formation is flatter. The well-formed length of the upper surface of the weld reached $68 \mathrm{~mm}$, and the maximum bridging gap was $1.36 \mathrm{~mm}$. The weld seam also collapsed between 50-68mm, for the same reasons as above. From the perspective of the formation of the back of the weld, the entire weld was not completely penetrated. Even when the molten pool collapsed at $50-68 \mathrm{~mm}$, it still did not melt through the entire workpiece. Because only the arc voltage is changed without changing the wire feed speed, the deposited amount is relatively insufficient in the case of a larger gap, so it cannot penetrate the entire workpiece. As the arc voltage continues to increase to $20 \mathrm{~V}$, the upper surface of the weld begins to deteriorate, and the length of the well formed is reduced. The upper surface of the weld becomes very flat and the remaining-height is very small. This is because the welding arc pressure increases due to the increase in arc voltage, the range of the arc becomes larger, and the molten pool is stressed in the lateral direction to spread more uniformly. Therefore, the melting width becomes larger, and the welding seam becomes flat. The back of the weld is fused, but the continuity is not good. Overall, the gap bridging capacity of welding is weakened. When the arc voltage is $24 \mathrm{~V}$, the forming of the upper surface of the weld continues to deteriorate, and the length of the good forming is further reduced. However, the formation of the back of the weld is further improved. Also, the back of the weld is basically permeable and 
relatively continuous. The maximum length of weld formation is $67 \mathrm{~mm}$, and the maximum gap that can be welded is $1.28 \mathrm{~mm}$. When the arc voltage is $28 \mathrm{~V}$, the formation of the upper surface of the weld continues to deteriorate, and the formation between the weld and the sidewall becomes discontinuous. Mainly because the droplet size becomes larger during the droplet transition, which makes the droplet heat different at different positions of the weld, resulting in uneven weld formation. At the same time, the back of the weld has begun to deteriorate. The maximum length of the weld can be formed is $50 \mathrm{~mm}$, and the maximum gap that can be welded is $1.0 \mathrm{~mm}$. When the arc voltage reaches $32 \mathrm{~V}$, the hybrid welding process is no longer stable and the weld cannot be formed. This is because the arc length is too long, the arc is easy to drift, the welding process is unstable, and the weld cannot be formed ${ }^{[8]}$.

Table 4 Effect of arc voltage on weld morphology under a variable gap in laser-MIG arc hybrid welding

\begin{tabular}{|c|c|c|}
\hline $\begin{array}{c}\text { Arc } \\
\text { voltage }(\mathrm{V})\end{array}$ & $\begin{array}{c}\text { Upper surface } \\
\text { morphology }\end{array}$ & $\begin{array}{l}\text { Lower surface } \\
\text { morphology }\end{array}$ \\
\hline 12 & & \\
\hline 16 & & \\
\hline 20 & 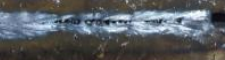 & \\
\hline 24 & & 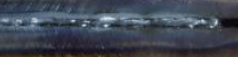 \\
\hline 28 & Nases $-\mathrm{ec}$ & 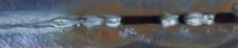 \\
\hline 32 & & $=x-\infty,-\infty$, \\
\hline
\end{tabular}

Taken together, it is found that the arc voltage can effectively improve the gap bridging ability of hybrid welding. Because the arc voltage affects the pressure of the 
welding arc, the formation of the weld seam, and the depth of the penetration. With the increase of arc voltage, the welding depth of hybrid welding increases significantly, and the forming status of the upper and back of the welding seam shows a trend of the opposite. The formation of the upper side of the weld gradually worsens and the formation of the back side gradually improves. It can be concluded from Figure 4 that the gap bridging ability of hybrid welding is the best when the arc voltage is $16 \mathrm{~V}$, and the gap bridging ability increases first and then decreases as the arc voltage increases.

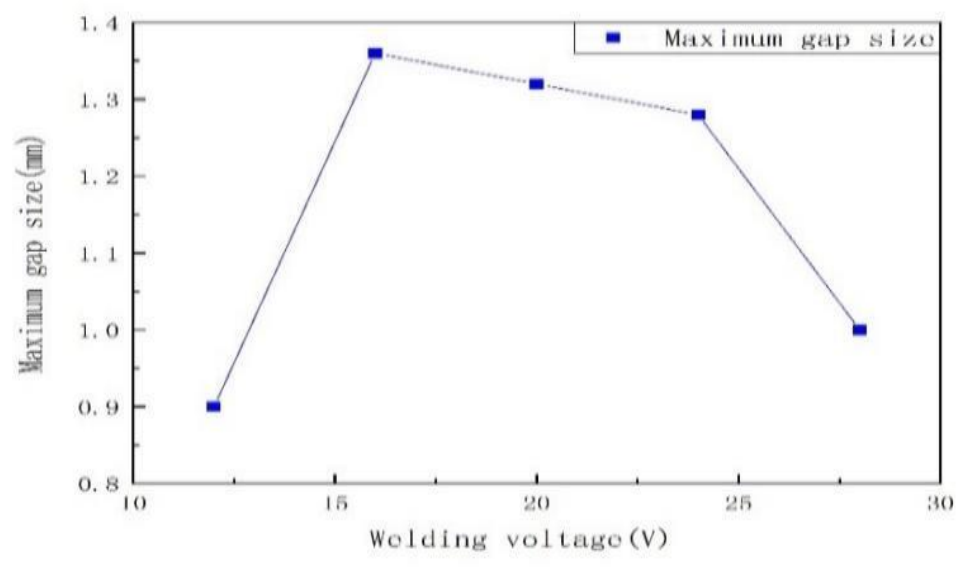

Fig.4 Effect of arc voltage to maximum gap sizes of laser-MIG arc hybrid welding

\subsection{Effect of laser-wire distance on gap bridging capability of Laser-MIG} arc hybrid welding

Table 5 shows the macroscopic morphology of the laser-MIG arc hybrid welding seam at a different laser-wire distance. When the laser-wire distance is increased from $-2 \mathrm{~mm}$ to $0 \mathrm{~mm}$, the weld formation is gradually improved, and the degree of penetration is getting higher and higher. Welding gap bridging ability is getting better. This is because part of the energy of the laser is transferred from the welding wire to the molten pool as the laser-wire distance continues to increases. When the arc heat input is unchanged, it is equivalent to increasing the total heat input to the molten pool. Part of the energy of the laser is still applied to the welding wire, ensuring a sufficient deposition amount, so that the weld can be penetrated ${ }^{[16]}$. As a result, the weld formation is improved and the gap bridging capability is enhanced. When the laser-wire distance is increased from $0 \mathrm{~mm}$ to $3 \mathrm{~mm}$, the forming of the upper surface of the weld gradually 
begins to deteriorate. The forming of the back of the weld seam is improved first and then worsened until the laser-wire distance is $4 \mathrm{~mm}$, it cannot be formed at all. This is because as the laser-wire distance continues to increase, and more energy from the laser is applied to the molten pool, which leads to excessive heat input, and therefore the upper surface of the weld is poorly formed. However, the formation of the back of the weld is better first and then gradually worse. The welding gap bridging ability is strengthened first and then drops sharply when the laser-wire distance is $4 \mathrm{~mm}$. It is speculated that because the laser-wire distance just started to become positive, the weld droplet transition mode did not change, the welding process was stable, and the back of the weld could still be fused. When the laser-wire distance continues to increase, the welding current increases, and arc voltage is low, and the droplet transfer mode changes to a short-circuit transition, the welding process becomes unstable, and the weld formation becomes worse. The detailed mechanism can be seen in the analysis of highspeed camera images in Experiment 3.3. When the laser-wire distance is $4 \mathrm{~mm}$, the laser energy is almost completely applied to the molten pool. The excessive total heat input causes the welding process to be unstable and the weld cannot be formed.

As can be seen from Figure 5, in general: With the increase of the laser-wire distance, the gap bridging ability of laser-MIG arc hybrid welding has been significantly improved, and the peak value is reached when the distance of the optical wire is $3 \mathrm{~mm}$. It is because the current of the MIG arc increases due to the increase of the laser-wire distance, and the range of the arc column becomes larger. Besides, as the laser-wire distance increases, the energy of the laser is transferred into the molten pool, and the increase in the total heat input is equivalent to increasing the deposition amount, so the gap bridging capability is improved. But it can also be seen that with the increase of the laser-wire distance, the welding process gradually becomes unstable. Weld formation is gradually worsening, and even unable to form. This is because the laserarc interaction becomes worse as the laser-wire distance increases. The arc becomes more unstable under high speed welding, so the welding process is unstable.

Table 5 Weld morphology of laser-MIG arc hybrid welding under different laser-wire 
distance

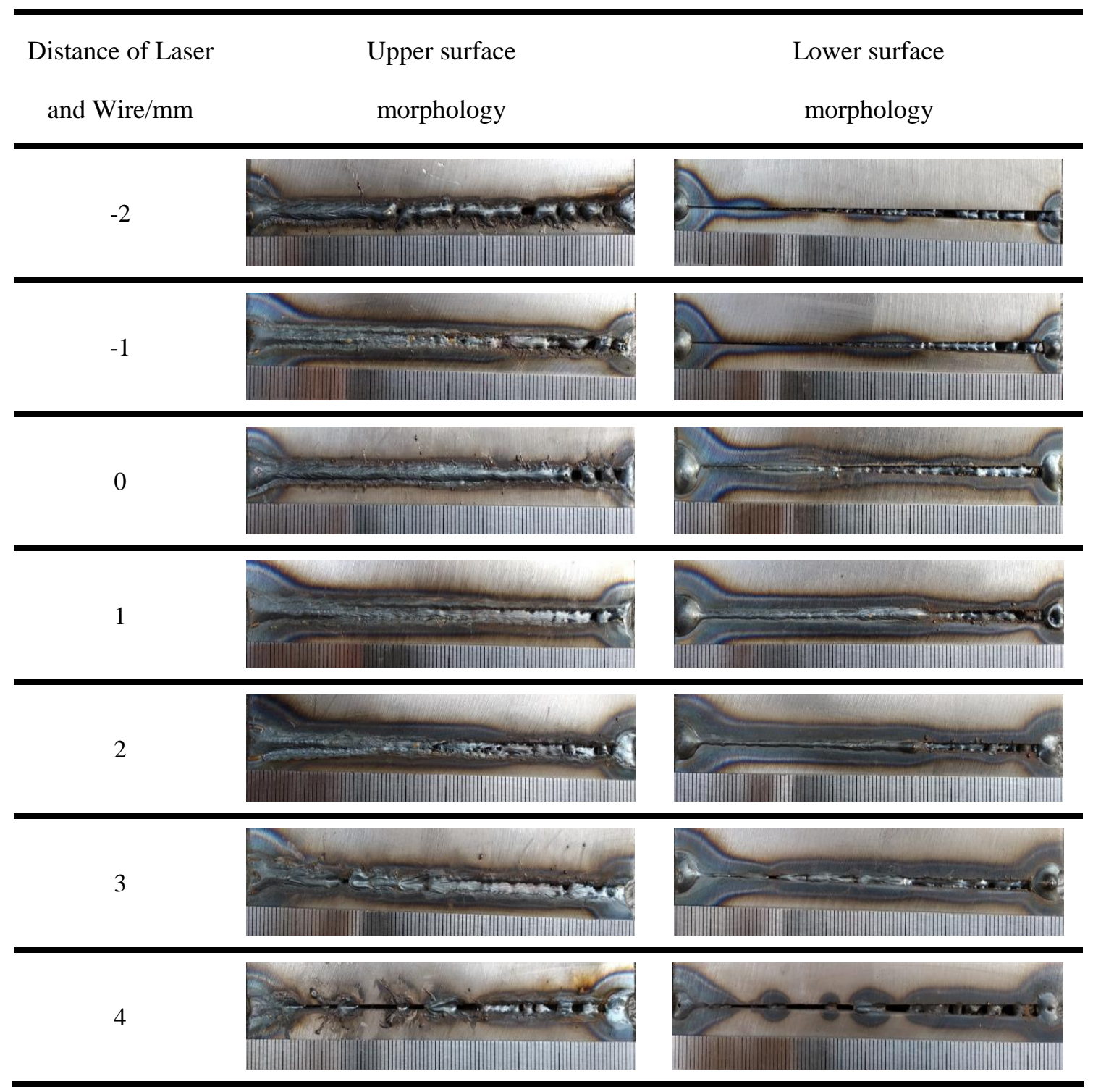

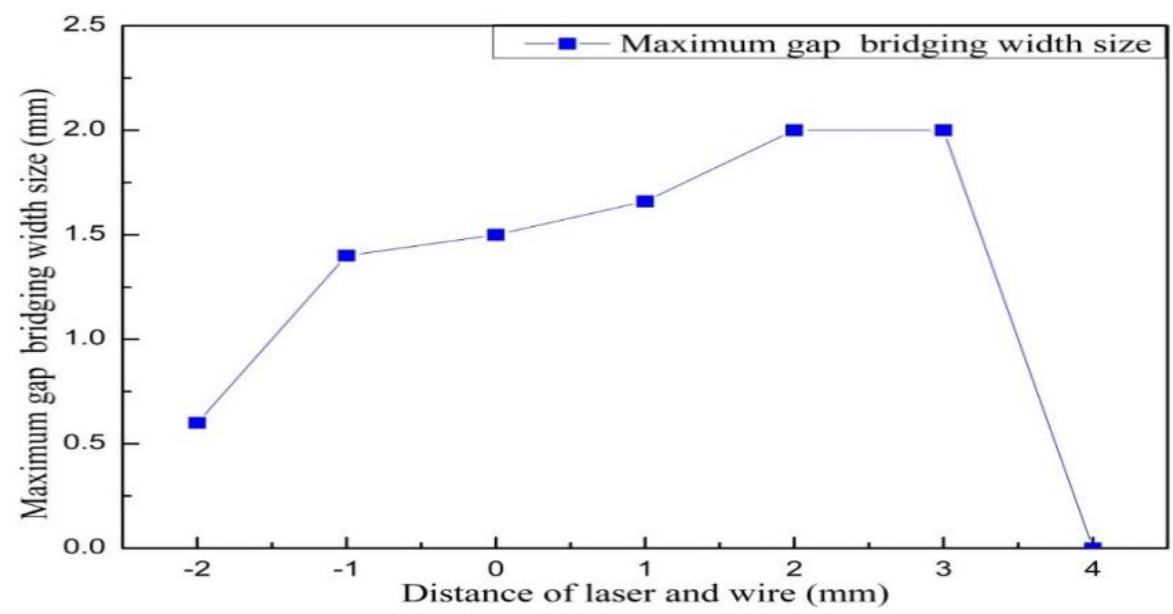

Fig.5 Effect of laser-wire distance on gap bridging ability of laser-MIG arc hybrid welding

\subsection{Effect of wire feed speed on gap bridging capability of Laser-MIG arc}




\section{hybrid welding}

Equation 4 shows the relationship between the volume of wire feed in unit time, wire feed speed, and wire diameter. However, in the experiment, there is less spatter. If the small factors such as metal evaporation and spatter are not considered, the deposited amount in unit time during the welding process can be approximately equal to the volume of wire feed per unit time. Considering the effect of welding speed, the length of welding in a unit time is $\mathrm{v}_{2}$, and the deposited amount in the length of $\mathrm{v}_{2}$ in unit time is $\mathrm{v}_{1} \times \pi(\mathrm{r} / 2)^{2}$. Therefore, the differential of the deposited amount per unit time can be expressed as shown in Equation 5.

$$
\begin{aligned}
\mathrm{S} & =\mathrm{v}_{1} \times \pi(\mathrm{r} / 2)^{2} \\
\mathrm{dC} & =\frac{\mathrm{v}_{1} \times \pi(\mathrm{r} / 2)^{2}}{V_{2}}
\end{aligned}
$$

Where $\mathrm{S}$ is the volume of wire feed in unit time, $\mathrm{v}_{1}$ is the wire feed speed, $\mathrm{r}$ is the diameter of the welding wire, $\mathrm{C}$ is the differential of deposited amount in unit time, and $\mathrm{v}_{2}$ is the welding speed.

In this experiment, we studied the variable gap butt weld, so the deposited amount directly determines the gap bridging capability during welding. Because the welding speed and wire diameter are fixed values, the deposited amount is mainly affected by the wire feed speed. In this experiment, the variable gap butt joint method was used to study the effect of wire feed speed on the gap bridging capability of the hybrid welding. Table 6 shows the macro morphology of the front and back of the weld seam under different wire feed speeds. It can be seen from Table 6 that with the increase of wire feed speed, the gap bridging ability of hybrid welding is continuously improved. Because the variable gap butt joint method is used in the experiment, it is easy to show the phenomenon that the weld bead remaining-height is large when the butt gap is small, and the weld bead remaining-height is reduced when the butt gap is increased. When the wire feeding speed is $4 \mathrm{~m} \cdot \mathrm{min}^{-1} \sim 7 \mathrm{~m} \cdot \mathrm{min}^{-1}$, the upper and lower surfaces of the weld seam gradually become better. The increase of the weld bead remaining-height reflects the continuous increase of the deposited amount. However, when the wire feeding speed is between $7 \mathrm{~m} \cdot \mathrm{min}^{-1}$ and $10 \mathrm{~m} \cdot \mathrm{min}^{-1}$, although the gap bridging ability 
of the hybrid welding is still improving, the formation of the weld surface gradually deteriorates. This is because the unitary welding machine is used in the experiment, and increasing the wire feeding speed will increase the welding current. The continuous increase in welding current and wire feed speed will eventually lead to instability in the welding process.

Table 6 Effect of wire feeding speed on weld morphology under a variable gap in laser-MIG arc hybrid welding

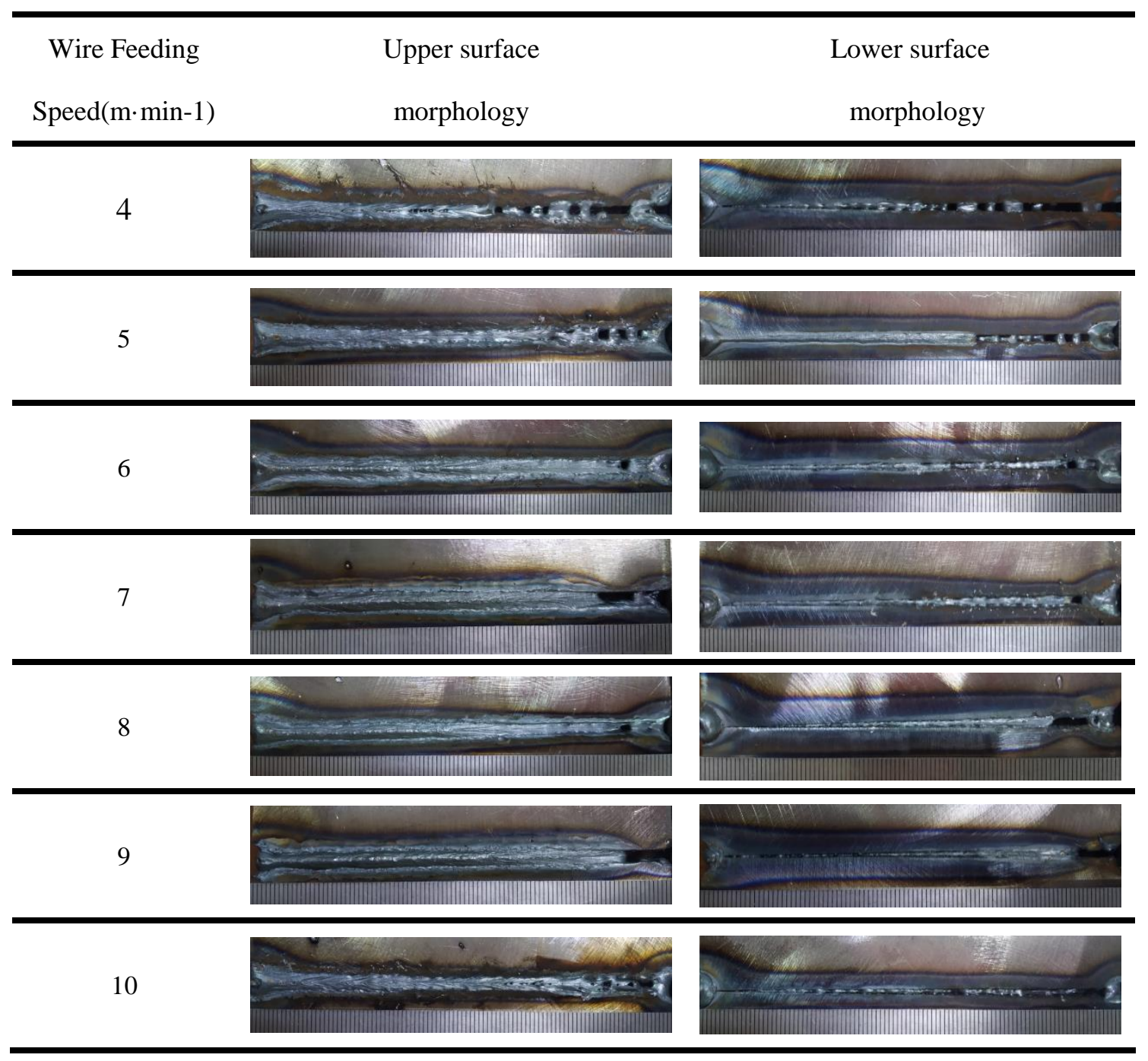

Figure 6 reflects the relationship between the gap bridging capability of laser-MIG arc hybrid welding and the wire feed speed in the experiment. It can be seen that the gap bridging capability of the hybrid welding is proportional to the wire feed speed. This is consistent with the results shown in Equation 2. The increase in wire feed speed will increase the volume of the weld gap. 


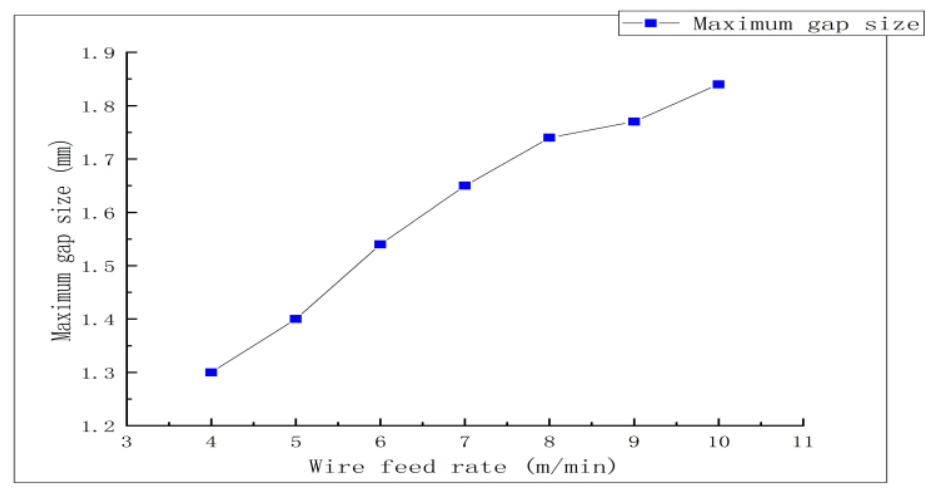

Fig.6 Effect of wire feeding speed on gap bridging ability of laser-MIG arc hybrid welding

\subsection{Forming mechanism of laser-MIG arc hybrid welding}

In this experiment, under the $1 \mathrm{~mm}$ butt gap, the laser-wire distance of the hybrid welding was changed to study the formation mechanism of the weld. By observing the macro and micro morphology of the weld, compare the changes of arc current and voltage during the welding process, analyzing the mode and frequency of droplet transfer to explore the effect of laser-wire distance on the forming mechanism of the laser-MIG arc hybrid weld. The schematic diagram of the relative position of the laser and MIG welding wire at a different laser-wire distance is shown in Figure 7.

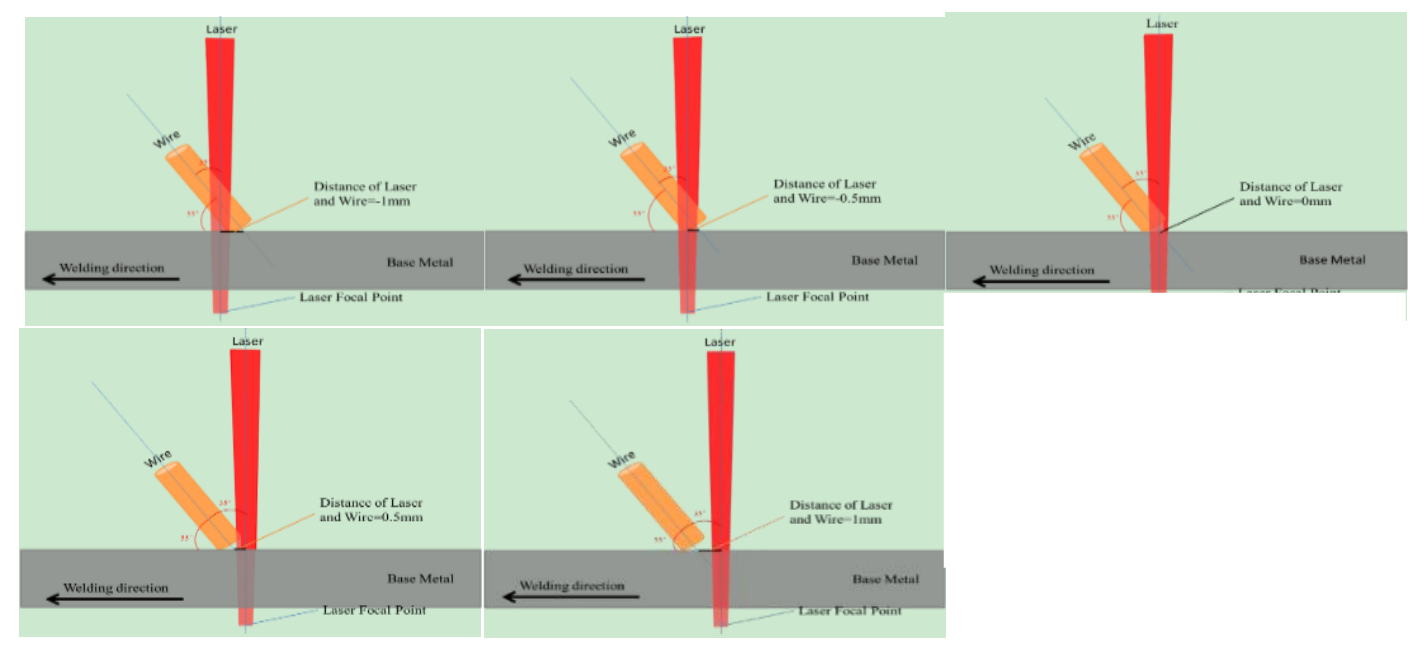

Fig. 7 Schematic diagram of the relative positions of laser and MIG welding wires at different laser-wire distances

Tables 7 and 8 show the macro and micro morphology of laser-MIG arc welding welds seam. In Tables 7 and 8, we can see that: When the laser-wire distance is $-1 \mathrm{~mm}$, the weld surface is formed uniformly with less spatter. But the remaining-height is high and the base material is not fusion penetration. After analysis, it should be that the arc 
current of the melting sidewall is insufficient, and the laser energy mainly acts on the welding wire, resulting in small heat input, so the base metal has not been fusion penetration. Observing the micro-morphology of the weld can reveal: There is no undercut in the weld, there is no fusion at the side wall of the weld and there are dense holes in the remaining-height. According to the analysis, it is believed that the lowmelting-point metal vapor was not escaped in time and was enriched in the remainingheight of the weld. There are also a few pores at the fusion line on the side wall of the weld. The analysis believes that the insufficient energy width of the heat source causes the gas attached to the side wall of the workpiece not to be discharged in the first time. When the laser-wire distance is $-0.5 \mathrm{~mm}$. The surface of the weld seam is well formed, but the penetration depth (close to that of the laser-wire distance at $-1 \mathrm{~mm}$ ) is still small, and the base material is not penetrated. It can be seen from Fig. 6 that when the laserwire distance is $-1 \mathrm{~mm}$ and $-0.5 \mathrm{~mm}$, the laser energy mainly acts on the welding wire, so when the laser-wire distance is changed, the penetration depth is almost unchanged. Observing the micro-morphology of the weld seam, it was found that there is undercut in the hybrid weld seam, the side wall is not fused, and the air hole is near the fusion line of the side wall. The reason is similar to that of the laser-wire distance of $-1 \mathrm{~mm}$. When the laser-wire distance is $0 \mathrm{~mm}$, the weld surface is well formed and the weld penetration is significantly increased compared with the negative laser-wire distance. The analysis shows that the laser is acting on the welding wire and the molten pool at the same time and the laser acting on the molten pool plays a role in increasing the penetration depth. According to the microscopic morphology of the weld, it can be known that the side wall of the base metal is still not fused when the laser-wire distance is $0 \mathrm{~mm}$, and there are still pores near the fusion line of the side wall of the base metal. When the laser-wire distance is $0.5 \mathrm{~mm}$, the weld surface is not full and there are humps on the back. However, the cross-section morphology of the weld is good, and the macromorphology of the weld is free of defects. Besides, there are no common defects such as unmelted sidewalls of the base material and air holes near the fusion line of the base material. When the laser-wire distance is $1 \mathrm{~mm}$, the surface morphology of the weld is significantly deteriorated. But the weld penetration is further increased. From the 
micro-morphology of the weld, we can observe undercuts and pores near the fusion line of the base metal. In general, when the laser-wire distance is $0.5 \mathrm{~mm}$, the penetration and formation of the weld are better, and the weld defects are less.

Table 7 Morphology of laser-MIG arc hybrid welding seams at different laser-wire distance

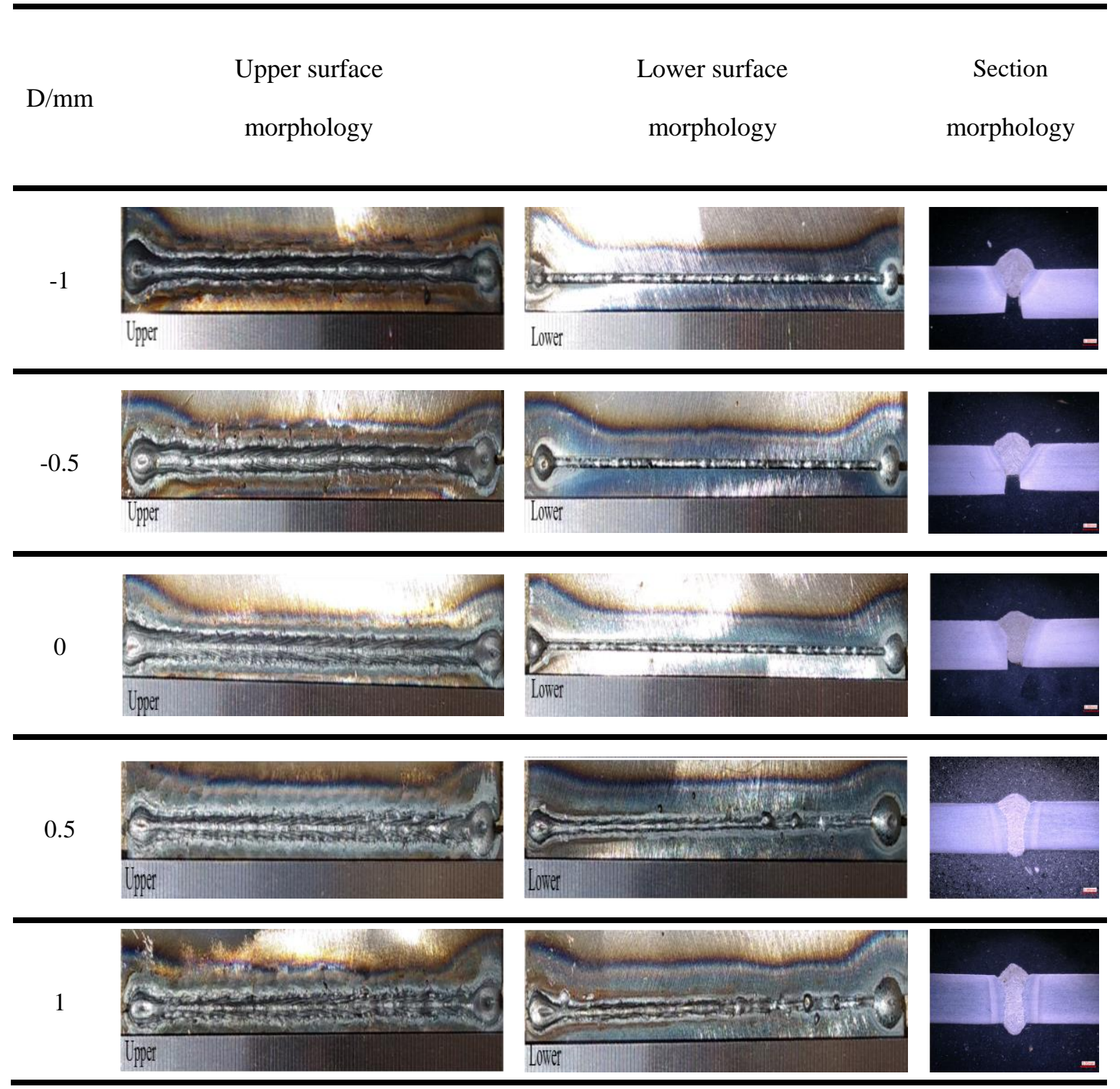

Table 8 compares the welding current and voltage waveforms of different laserwire distance. When the laser-wire distance is $-1.0 \mathrm{~mm}$, the average welding current of the hybrid welding is $183 \mathrm{~A}$, the average short-circuit current is $310 \mathrm{~A}$, and the average arc voltage is about $16 \mathrm{~V}$. At this time, the welding process is relatively stable ${ }^{[20]}$. When the laser-wire distance is $-0.5 \mathrm{~mm}$, it can be known that the short-circuit current is smaller than that when the laser-wire distance is $-1 \mathrm{~mm}$. The average welding current and voltage are basically equal. It can be known that the welding process is more stable. 
When the laser-wire distance is $0 \mathrm{~mm}$, the welding current and voltage waveforms become significantly denser. That is, the droplet transfer frequency of hybrid welding is significantly accelerated. And the average short-circuit current is lower than that under the negative laser-wire distance. The decrease of average welding current and voltage is not significant, and the stability of the welding process is further improved. When the laser-wire distance is $0.5 \mathrm{~mm}$, the average welding current and short-circuit current increase significantly. This is because the laser energy acts more on the molten pool than the welding wire, which is equivalent to increasing the wire feeding speed, so the welding current is increased. When the laser-wire distance is $1.0 \mathrm{~mm}$, the welding current and voltage waveforms both fluctuate sharply, and the short-circuit current becomes very large. Means welding arcing becomes very difficult and the welding process becomes less stable.

It can be seen from Fig. 8 that the change of the laser-wire distance has a significant effect on the current and voltage. When the laser-wire distance is increased from -1mm to $0 \mathrm{~mm}$, the welding current and voltage become stable, and the welding current decreases. The welding process becomes more stable. When the laser-wire distance is increased from $0 \mathrm{~mm}$ to $1 \mathrm{~mm}$, the welding current starts to increase. And when the laserwire distance is $1 \mathrm{~mm}$, the current and voltage become extremely unstable. The stability of the welding process becomes poor. The ratio of the average welding current to the short-circuit current is the largest when the laser-wire distance is $0 \mathrm{~mm}$. It can be known that the welding process is the most stable at this time ${ }^{[19]}$. Regardless of the increase or decrease of the laser-wire distance, the ratio of the average welding current to the shortcircuit current will decrease, and the welding stability will deteriorate. It can be known that under the same process parameters, the change of the laser-wire distance will affect the energy of the welding arc, and then affect the welding stability and heat input. It can be seen from Fig. 9 that as a whole, with the increase of the laser-wire distance, the penetration depth and arc current of the hybrid welding has increased. It can be known from this that the laser-wire distance controls the arc current and the amount of laser energy acting on the molten pool, which in turn affects the weld depth and ultimately affects the welding gap bridging ability. 


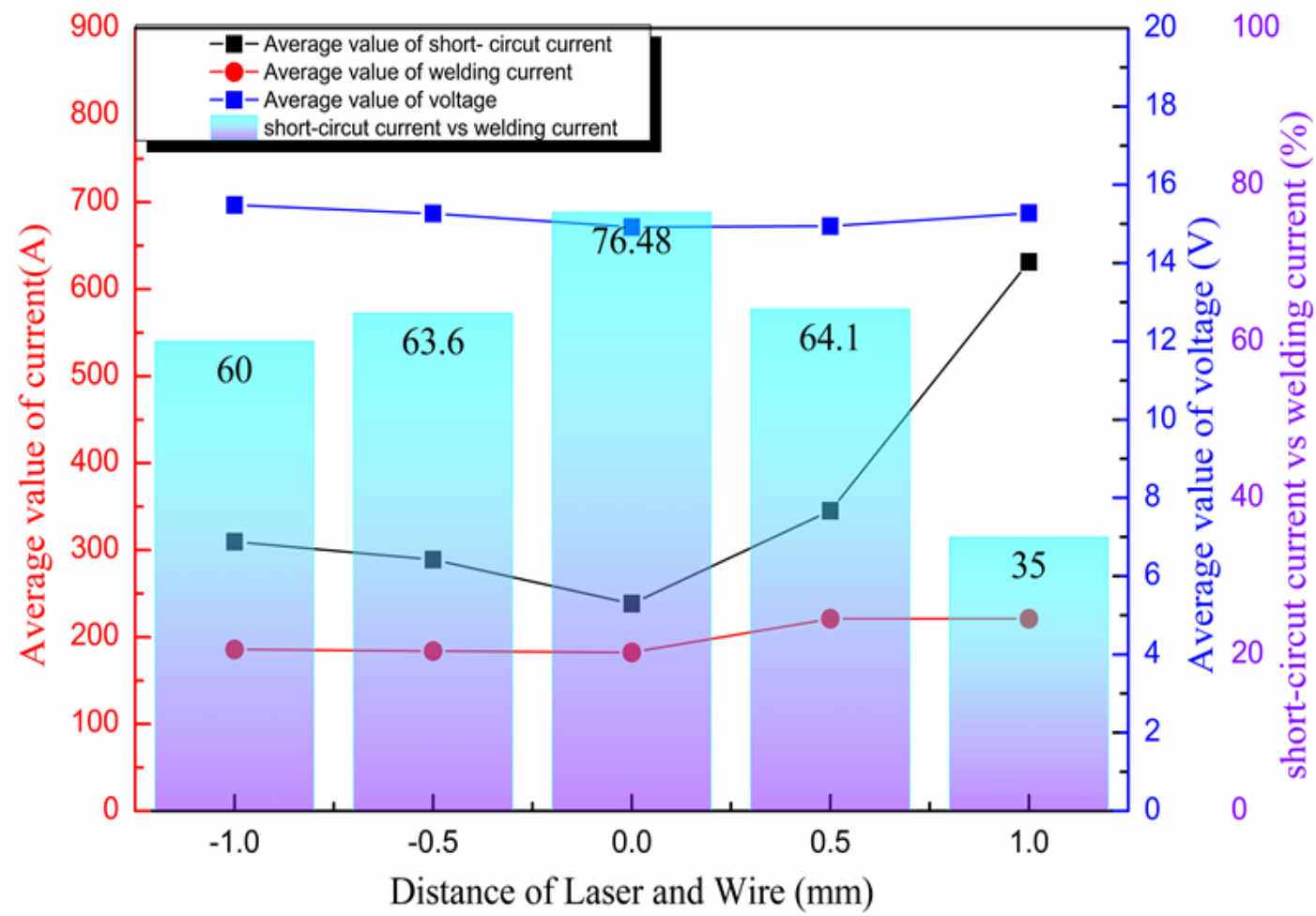

Fig.8 The influence of laser-wire distance on laser-arc welding stability

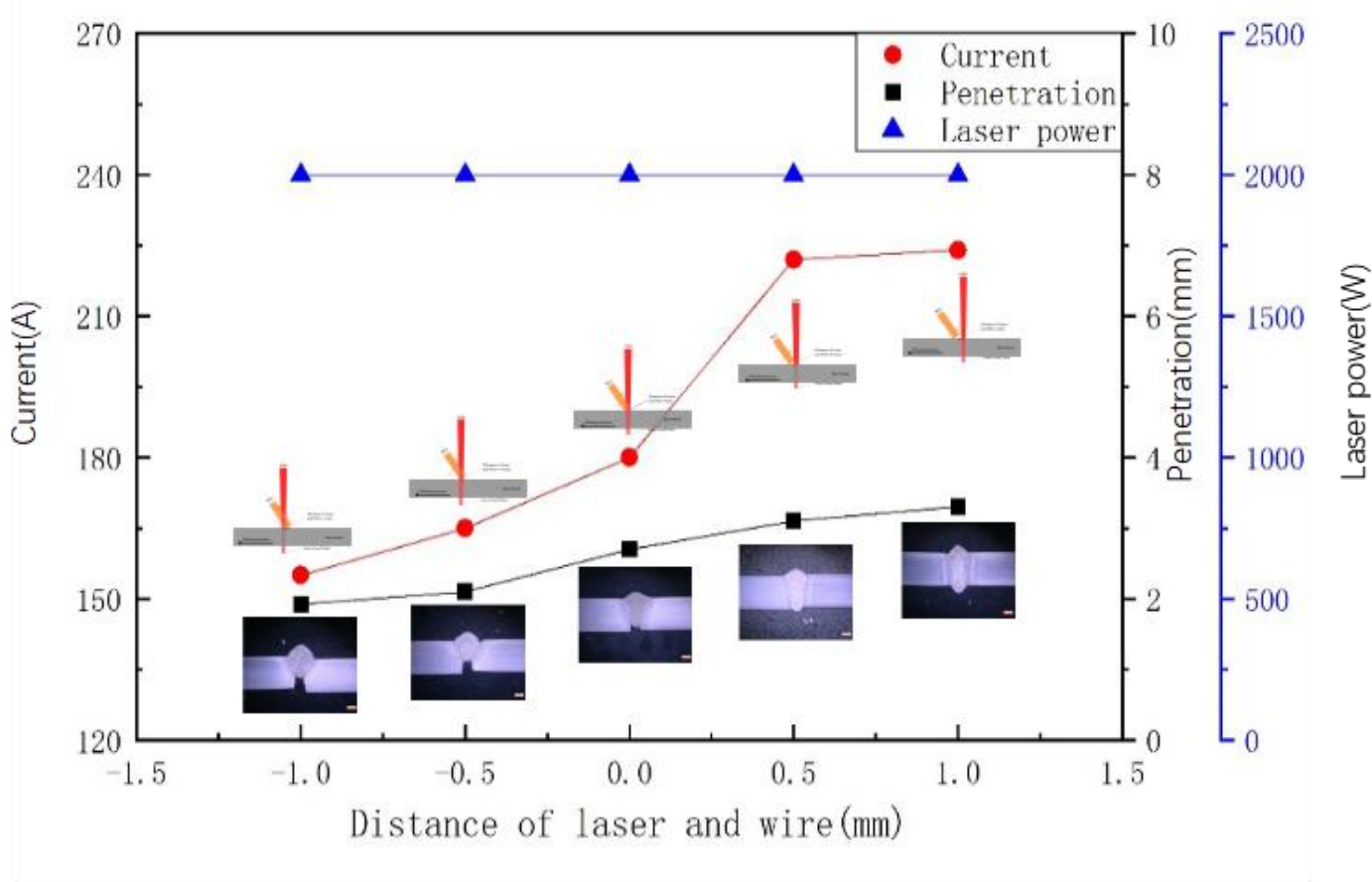

Fig.9 Effect of laser-wire distance on the penetration of hybrid welding

Table 8 Micro-morphology of composite welds and current and voltage waveforms of composite welds at different laser-wire distance 


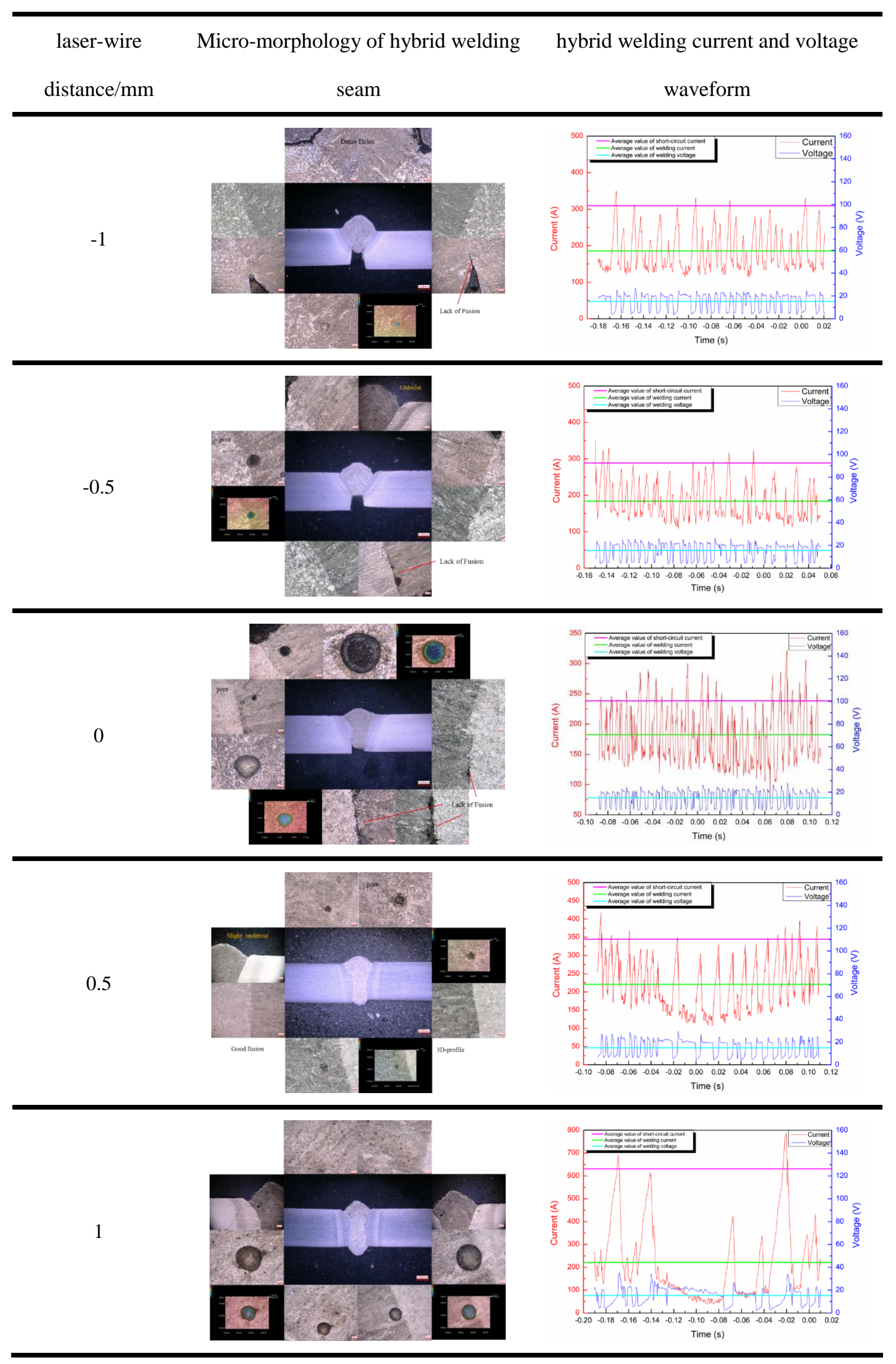

In this experiment, high-speed photographic images at five different laser-wire 
distance were collected to analyze the droplet transition during welding. As shown in Figure 10, where D represents the laser line distance, I represents the welding current, and $\mathrm{U}$ represents the arc voltage. When the laser-wire distance is $-1.0 \mathrm{~mm}$, the laser energy is mainly used to melt the welding wire which equivalent to increased wire feeding speed or can be regarded as hot wire MIG welding. The increase of wire feeding speed makes the welding current larger and the welding process less stable. There are two transitions in the droplet transfer of hybrid welding. The first transition of the droplet fails to complete the transition, and the second transition is a complete transition of the droplet. This is because it takes a certain time for the droplet to form a necking, while the continuous laser wave still acts on the welding wire, and the welding wire continues to melt. At this time, the current is large, and the force of the current forming the necking pulls up the droplets formed when the laser melts the welding wire. Hence the phenomenon of incomplete transition is formed. Due to the phenomenon of two droplet transitions, the period of droplet transition is relatively long, which is $20.57 \mathrm{~ms}$. When the laser-wire distance is $-0.5 \mathrm{~mm}$, the droplet transfer of the hybrid welding is almost the same as that when the laser-wire distance is $-1.0 \mathrm{~mm}$. However, when the laser-wire distance is $-0.5 \mathrm{~mm}$, the period of the droplet transfer is slightly shorter at $19.58 \mathrm{~ms}$. It can be seen from Figure 9 that when the wire spacing is $0 \mathrm{~mm}$, the droplet transfer frequency of the hybrid welding is very high, and the droplet transition period is 5.83ms. (a) (c) in Fig. 10 are in the arcing state, and (d) (f) in Fig. 10 are in the bridge-liquid transition state. When the laser-wire distance is $0 \mathrm{~mm}$, the droplet transition presents a hybrid transition method of short-circuit transition method and bridge-liquid transition method. The transition frequency of this droplet transfer method is very high, and the bridge-liquid transition stability is well. Therefore, the stability of the hybrid welding has been significantly improved. When the laser-wire distance is $0.5 \mathrm{~mm}$, the droplet transition is similar to when the laser-wire distance is $0 \mathrm{~mm}$, which is a mixed transition form of short-circuit transition and bridge-liquid transition, as shown in $(\mathrm{d}) \sim(\mathrm{f})$ in Figure 10. However, the transition frequency of the droplet drops when the laser-wire distance is $0.5 \mathrm{~mm}$, and the transition period is $11 \mathrm{~ms}$. 
Here, we can explain the problem mentioned in the previous experiment in 3.2: When the laser-wire distance starts to increase from $0 \mathrm{~mm}$, the forming of the back of the weld becomes better and then worse, rather than the expected phenomenon that the forming of the back of the weld continues to deteriorate. The droplet transfer mode has not changed at the beginning, the droplet transfer mode is still a hybrid transfer method of the short-circuit transfer method and the bridge-liquid transfer method, and the droplet transfer period becomes longer (still relatively short). The welding current also increases a lot, which is equivalent to increasing the deposition amount in a disguised manner. As a result, the weld is more permeable and the back formation will be better. As the laser-wire distance continues to increase, as show in figure 8, the welding current is high and the arc voltage is low, and the droplet transfer mode changes to a shortcircuit transition. Also, the short-circuit current is very high at this time, the ratio of short-circuit current to welding current is very small. At the moment under short circuit conditions, strong current flows through the liquid bridge. Under the influence of the electromagnetic contraction force generated by the strong current, the liquid bridge is broken. At the same time, the liquid bead at the end of the welding wire rises up to form a spatter ${ }^{[19]}$. As a result, the weld formation becomes worse. The droplet transition period of the hybrid welding wire with $1.0 \mathrm{~mm}$ laser-wire distance becomes $17.16 \mathrm{~ms}$, and the melting of the welding wire is completely dependent on the arc energy. It can be known that the arc root of the arc in Figure 10 (b) is attracted by the laser keyhole. The droplet size is large, and finally the short-circuit transition into the molten pool.

Therefore, when the laser-wire distance is zero, the stability of the hybrid welding is the best, and the droplet transfer speed is the fastest. Droplet transition presents a mixed transition form of short circuit transition and liquid-bridge transition. The bridgeliquid transition is a typical stable transition form of laser filler wire welding. It can be known that the welding process is very stable at this time. However, although the welding process is the most stable and the droplet transfer frequency is the fastest when the laser-wire distance is $0 \mathrm{~mm}$, its bridging ability, and penetration depth are not as good as those when the laser-wire distance is $0.5 \mathrm{~mm}$. When the laser-wire distance is $0.5 \mathrm{~mm}$, the stability of the welding process and the mode and frequency of the droplet 
transfer are very close to the laser-wire distance of $0 \mathrm{~mm}$. Meanwhile, it has better gap bridging capabilities and fewer weld defects. Therefore, when the laser-wire distance is $0.5 \mathrm{~mm}$, the bridge capacity, welding stability, arc energy utilization rate, and droplet transfer frequency are all good

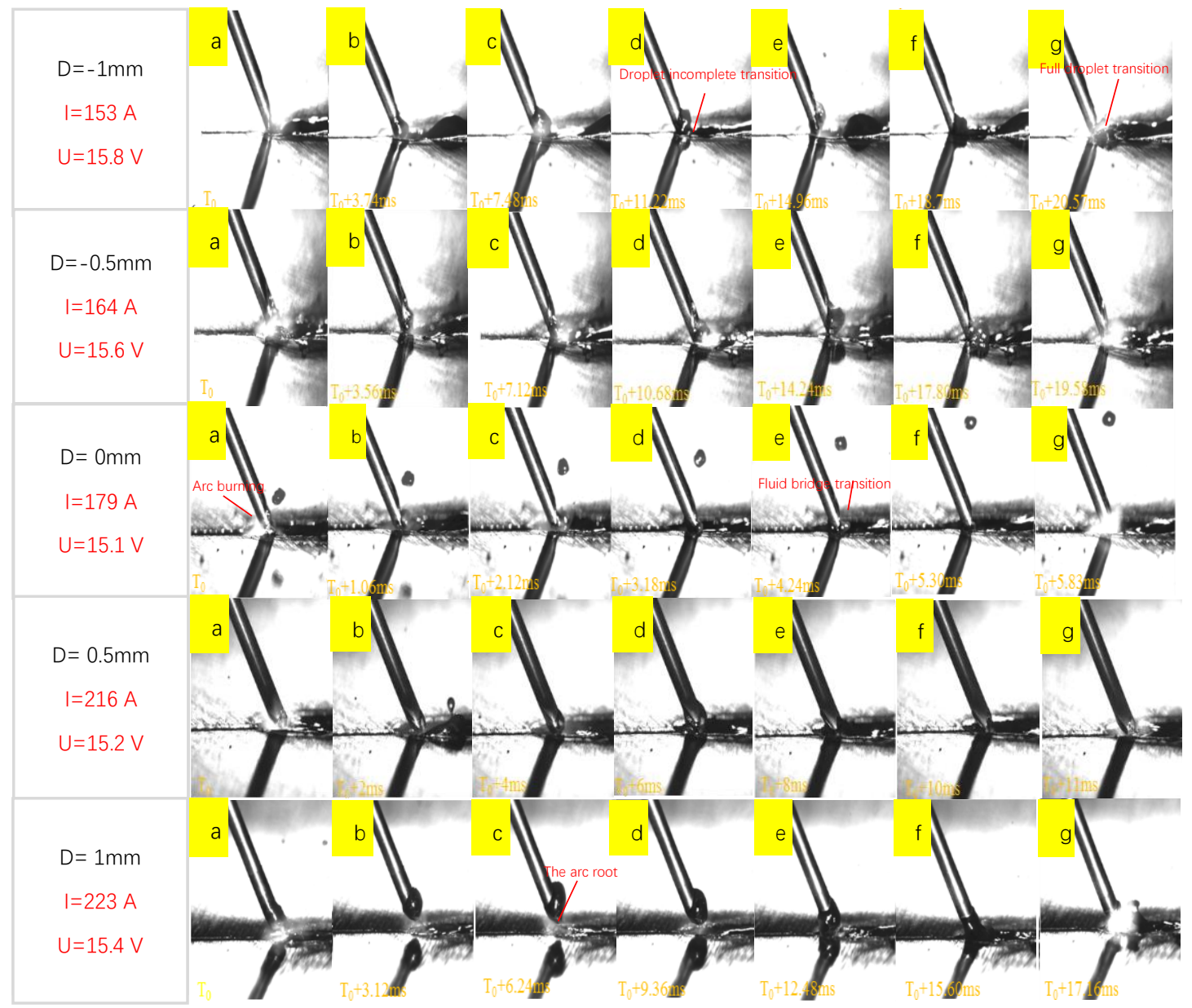

Fig.10 High-speed photography of droplet transfer of laser-MIG arc hybrid welding at different laser-wire distance

\section{Conclusion}

(1) In this paper, laser-MIG arc hybrid welding is used to weld low-alloy highstrength steel with a thickness of $3 \mathrm{~mm}$, and a laser-MIG arc hybrid welding process under large gap conditions is developed. The best laser-wire distance is $0.5 \mathrm{~mm}$. For other optimal process parameters, please refer to Table 3 in the article. Variations in arc voltage can effectively change the bridging ability of laser-MIG arc hybrid welding. The arc voltage not only affects the pressure of the welding arc, but also affects the formation and penetration of the weld. With the increase of arc voltage, the penetration depth of hybrid welding increases 
significantly, and the continuity is better. However, with the increase of arc voltage, the forming of the upper surface of the weld gradually deteriorates. As the arc voltage increases, the weldable gap increases first and then decreases. The gap bridging capability of laser -MIG arc hybrid welding is the best when the arc voltage is $16 \mathrm{~V}$.

(2) With the increase of the laser-wire distance, the gap-bridging ability of laserMIG arc hybrid welding has been significantly improved. But at the same time, the welding process is gradually unstable, and the weld formation is gradually worsening, or even unable to form. Increasing the wire feed speed can greatly increase the deposited amount during welding, thereby improving the gapbridging ability of laser-MIG arc hybrid welding. However, blindly increasing the wire feed speed will cause instability in the welding process, affecting the weld formation. In addition, different wire feed speeds are required for different butt gaps to ensure the gap bridging ability of the hybrid welding.

(3) The mechanism of the effect of laser-wire distance on the weld formation of laser-MIG arc hybrid welding: Laser-assisted welding wire melting improves the stability of welding. Adjusting the laser-wire distance can change the energy distribution of the laser on the welding wire and the molten pool. Properly adjusting the laser-wire distance can also effectively improve the arc energy utilization rate. Then it further controls the arc current, weld penetration, and droplet transition mode and frequency (welding stability). Ultimately it can affect the gap bridging capability and weld formation of laser-MIG arc welding.

(4) When the laser-wire distance is zero, the stability of the hybrid welding is the best, and the droplet transfer speed is the fastest. However, considering the factors such as the welding gap bridging ability, the welding seam forming effect, and the welding seam defect, the optimum process parameters are the laser-wire distance of $0.5 \mathrm{~mm}$.

\section{Acknowledgements}


This research was supported by Natural Science Foundation of China (51605276, 51905333), Shanghai Sailing Program (19YF1418100), Shanghai Science and Technology Committee Innovation Grant (17JC1400600, 17JC1400601, 19511106400, 19511106402), Karamay Science and Technology Major Project (2018ZD002B), Aid for Xinjiang Science and Technology Project (2019E0235), Shanghai Local Colleges and Universities Capacity Building Special Plan Project (19030501300).

\section{References}

[1]Bunaziv I, Akselsen O M, Frostevarg J et al (2018) Laser-arc hybrid welding of thick HSLA steel. J Mater Process Tech 259:75-87

[2]Bunaziv I, Frosteevarg J, Akselsen O M et al (2018) The penetration efficiency of thick plate laser-arc hybrid welding. Int J Adv Manuf Tech 97:2907-2919

[3]Steen Erik Nielsen (2015) High Power Laser Hybrid Welding-Challenges and Perspectives. Physics Procedia 78:24-34

[4]E. Le Guen, R. Fabbro, M. Carin, F. Coste, P. Le Masson (2011) Analysis of hybrid Nd: Yag laser-MAG arc welding processes. Opt Laser Technol 43:1155-1166

[5]Turichina G, Tsibulskiya I, Kuznetsova M, et al (2015) Influence of the Gap Width on the Geometry of the Welded Joint in Hybrid Laser-Arc Welding. Physics Procedia 78:14-23

[6]Bappa Acherjee (2018) Hybrid laser arc welding: State-of-art review. Opt Laser Technol 99:6071

[7]Chuang Cai,Jiecai Feng,Liqun Li,Yanbin Chen (2016) Influence of laser on the droplet behavior in short-circuiting, globular, and spray modes of hybrid fiber laser-MIG welding. Opt Laser Technol 83:108-18

[8]Mahmoud Moradi, Majid Ghoreishi, Jan Frostevarg, Alexander F.H. Kaplan (2013) An investigation on stability of laser hybrid arc welding. Opt Laser Eng 51:481-487

[9]Shuangyu Liu, Shixian Chen, Qinghua Wang, et al (2017) Analysis of plasma characteristics and conductive mechanism of laser assisted pulsed arc welding. Opt Laser Eng 92:39-47

[10]Shuangyu Liu, Fengde Liu, Chunying Xu, et al (2013) Experimental investigation on arc characteristic and droplet transfer in CO2 laser-metal arc gas (MAG) hybrid welding. Int J Heat 
Mass Tran 62:604-611

[11]Kah P, Salminen A, Martikainen J (2011) The analysis of shielding gases in laser-arc hybrid welding processes. P I Mech Eng B-J Eng 225:1073-82

[12]Xiaoyi Yang, Hui Chen, Zongtao Zhu, et al (2019) Effect of shielding gas flow on welding process of laser-arc hybrid welding and MIG welding. J Manuf Process 38:530-542

[13]Yunfei Meng, Ming Gao, Xiaoyan Zeng (2018) Quantitative analysis of synergic effects during laser-arc hybrid welding of AZ31 magnesium alloy. Opt Laser Eng 111:183-192

[14]Guo Tang, Xu Zhao, Rendong Li, et al (2020) The effect of arc position on laser-arc hybrid welding of 12-mm-thick high strength bainitic steel. Opt Laser Technol 121:105780

[15]J.L. Zou, S.K. Wu, R.S. Xiao, F. Li (2015) Effects of a paraxial TIG arc on high-power fiber welding. Mater Design 86:321-327

[16]Shuangyu Liu, Fengde Liu, Hong Zhang, et al (2012). Analysis of droplet transfer mode and forming process of weld bead in $\mathrm{CO}_{2}$ laser-MAG hybrid welding process. Opt Laser Technol 44:1019-1025

[17]Shuangyu Liu, Yanqing Li, Fengde Liu, et al (2016). Effects of relative positioning of energy sources on weld integrity for hybrid laser arc welding. Opt Laser Eng 81:87-96

[18]Zhang Wang, An Investigation of Dynamical Metal Transfer and Plasma Interaction During Laser-GMAW-p Hybrid Welding, Shanghai, Shanghai Jiao Tong University, 2014.

[19]Shuangyu Liu, Fulong Zhang, Shengnan Dong, et al (2018). Characteristics analysis of droplet transfer in laser-MAG hybrid welding process. International Journal of Heat and Mass Transfer $121: 805-811$

[20]Guolong Ma, Liqun Li, Yanbin Chen (2017) Effects of beam configurations on wire melting and transfer behaviors in dual beam laser welding with filler wire. Opt Laser Technol 91:138148

[21]Farrokhi F, Kristiansen M (2016) A practical approach for increasing penetration in hybrid laserarc welding of steel. Physics Procedia 83:577-586

[22]Zhang X, Mi G Y, Chen L, et al (2018) Microstructure and performance of hybrid laser-arc welded $40 \mathrm{~mm}$ thick 316L steel plates. J Mater Process Tech 259:312-319

[23]M.Wahba, M.Mizutani, S. Katayama (2016) Single pass hybrid laser-arc welding of 25mm thick square groove butt joints. Mater Design 97:1- 6 
